\title{
Glucose Metabolism of Human Mononuclear Cell Subpopulations
}

\author{
SUSAN STORCH, WAYNE KLEIN, STEPHEN A. FEIG, AND THEODORE HENDERSON
}

The Gwynne Hazen Cherry Memorial Laboratories and the Department of Pediatrics, UCLA School of Medicine, Los Angeles, California, USA

\section{Summary}

Previous studies have demonstrated metabolic dysfunction in the mononuclear cells of some children with abnormal cell-mediated immunity. Interpretation of these observations has been complicated by the extreme heterogeneity of cell types examined. The glycolytic metabolism of relatively enriched T-cells, non-T mononuclear cells (NTM), non-T lymphocytes (NTL), and monocytes was studied in an attempt to measure the metabolism of subpopulations of mononuclear cells.

Lactate production by monocytes was 11 times greater than that of T-cells and $2 \frac{1 / 2}{2}$ times greater than that of non-T lymphocytes. Exposure to phytohemagglutinin (PHA) stimulated glycolytic metabolism in T-cells but did not stimulate glucose utilization or lactate production in NTM. Even when T-cells were maximally stimulated by PHA, their observed metabolism was still lower than that of NTL. The ATP content of T lymphocytes and NTL was similar and was constant under the conditions of incubation. The initial ATP content of monocytes was higher than that of lymphocytes, and diminished during incubation.

Tricarboxylic acid cycle activity did not contribute significantly to ATP synthesis in any of the mononuclear cell subpopulations, under the conditions of incubation used in this study. Significant hexose monophosphate shunt activity was observed in all mononuclear cell types.

These studies demonstrate major metabolic differences between mononuclear cell subtypes. Any correlation of metabolic observation with clinical dysfunction of mononuclear cells requires the study of relatively pure cell populations.

\section{Speculation}

The reason for increased glycolysis in NTL is obscure. It may imply an immaturity of a portion of those cells, by analogy to the increased glycolytic activity of young erythrocytes. Alternatively, a subset of NTL may require increased ATP synthesis to perform its functions. In order to delineate these possibilities, methods must be developed which will allow the isolation of large numbers of $B$ and Null lymphocytes for metabolic and functional studies.

The performance of biologic functions by cells requires the expenditure of energy derived from cellular metabolism. Cellular dysfunction can be correlated with perturbations of energy metabolism by the dysfunctional cell. This correlation has been most strikingly demonstrated in erythrocytes, in which a variety of hemolytic anemias have been correlated with inherited disorders of glycolysis (17). More recent data suggest that the defect in platelets of patients with Wiskott-Aldrich Syndrome may be related to an inborn error of the Krebs Cycle (14).

The authors postulated that malfunction of human mononuclear leukocytes might be caused by or associated with disorders of energy metabolism. Several models of cell-mediated immune dysfunction were studied and diminished ATP content in the mononuclear cells of newborn infants (5) and patients with severe malnutrition (4) have been described. Specific correlation between a metabolic deficit and a cellular malfunction could not be made because of the heterogeneity of the cell populations studied. Although a specific cell function unique to one type of mononuclear cell can be studied in a heterogeneous group of cells, all mononuclear cells appear to depend upon glycolysis for their major energy supply (8). Therefore, metabolic differentiation between the subpopulations of mononuclear cells studied could not be made.

In order to clarify the metabolic dependence of mononuclear cell functions, the authors have studied the energy metabolism of enriched (partially purified) subpopulations of human mononuclear leucocytes. Major differences in glycolytic activity were observed and underscore the necessity to perform metabolic studies on relatively enriched populations of mononuclear cells.

\section{MATERIALS AND METHODS}

Specimens were obtained from consenting normal adults. Peripheral blood samples provided sufficient numbers of cells for the metabolic studies of whole mononuclear cells, enriched $T$ cells, and monocytes. In order to obtain sufficient cells for the metabolic studies of NTM and NTL, it was necessary to use the residue of single donor plateletpheresis packs (13).

Whole mononuclear cells (WMC) were harvested from the interface of a Ficoll-Isopaque gradient (2). A population enriched in T-cells was prepared from these WMC by either nylon wool column adherence (6) or by density gradient separation of $E$ rosettes over Ficoll-Isopaque (12). Populations enriched in NTM cells were prepared from the WMC pool by harvesting the residual cells at the interface of a gradient after the preparation of $\mathrm{E}$ rosettes (12). The NTL subpopulation was obtained by removal of most of the monocytes from the NTM samples. This was accomplished by exposure of NTM cells to iron particles (Lymphocyte Separator Reagent, Technicon Instruments Corporation, Tarrytown, NY) for $30 \mathrm{~min}$ at $37^{\circ} \mathrm{C}$ and subsequent density gradient centrifugation over Ficoll-Isopaque. NTL were then harvested from the interface. Monocytes (M) were partially purified by glass adherence. Adherent $M$ were then removed from the glass surface by exposure to $0.4 \%$ lidocaine (11).

Partially purified populations of mononuclear cells were washed three times in a balanced salt solution buffered with $10 \mathrm{mM}$ HEPES ( $\mathrm{pH}=7.4$ ). Cells in the final suspension were counted manually. Cell viability was assessed by trypan blue exclusion and was always greater than $90 \%$, before and after incubation.

The composition of the cell populations was assessed by Wright and Esterase stains of cytocentrifuge preparations. The percent of $T$ and Fc-receptor-bearing cells was measured by the preparation of $\mathrm{E}$ rosettes (10) and EA rosettes (19), respectively. The composition of each subpopulation of mononuclear cells is shown in Table 1.

Metabolic incubations were performed in a balanced salt solution, with added glucose and albumin, for a duration of $3 \mathrm{hr}$, as previously described (5). Some incubations were performed in the continuous presence of $100 \mu \mathrm{g} \mathrm{PHA} / \mathrm{ml}$. This concentration was chosen to provide maximal stimulation of glycolysis (5). Filtrates 
were prepared (5) and analyzed for glucose (15), lactate (9), and ATP (16). To measure Hexose Monophosphate Shunt (HMPS) activity, a parallel incubation was performed. The HMPS tube was stoppered with a Kontes rubber sleeve (Kontes Biomedical Products, Vineland, NJ 08360 (catalog K774250)) holding a plastic cup. At time $0,0.1 \mu \mathrm{Ci}$ of ${ }^{14} \mathrm{C}$-1-glucose (New England Nuclear Corp., Boston, MA 02118) was added to the incubation mixture. At the end of the incubation, $0.1 \mathrm{ml} 2 \mathrm{~N} \mathrm{H}_{2} \mathrm{SO}_{4}$ was added, by syringe, to the incubation mixture. Carbosorb (New England Nuclear Corp., Boston, MA 02118) $(0.2 \mathrm{ml})$ was added, by syringe, to the plastic cup to trap the released ${ }^{14} \mathrm{CO}_{2}$. After a 1-hr period of equilibration at room temperature, the contents of the cup were quantitatively transferred to a counting vial containing Permafluor V (New England Nuclear Corp.), and counted in a Packard Tricarb Liquid Scintillation Spectrometer (Packard Instrument Company, Inc., Downers Grove, IL 60515). The efficiency of the trapping procedure was determined by performing a cell-free incubation with $\mathrm{Na}_{2}{ }^{14} \mathrm{CO}_{3}$ (New England Nuclear Corp.). Tricarboxylic Acid (TCA) cycle activity was measured in an analogous manner, using ${ }^{14} \mathrm{C}-6$-glucose (New England Nuclear Corp.).

\section{RESULTS}

Glucose utilization by WMC was $60 \mathrm{nmoles} / 10^{7}$ cells $/ \mathrm{hr}$ (Table 2). Incubation with PHA resulted in a doubled rate of glycolysis. Glucose utilization by relatively purified T-cells was slightly lower than that of WMC and was appropriately stimulated by PHA.

NTM cells used glucose at a rate six times greater than that of $T$ cells. In contrast to T cells, PHA exposure did not affect the glycolytic rate of NTM cells. NTL glucose utilization was intermediate between $\mathrm{T}$ cells and NTM cells.

Lactate production by WMC was 104 nmoles $/ 10^{7}$ cells $/ \mathrm{hr}$ and doubled upon exposure to PHA. The rate of lactate production by enriched T cells was less than that of WMC and was nearly tripled by exposure to PHA. Lactate production by NTM cells was approximately 8 times greater than that of $\mathrm{T}$ lymphocytes, and was not affected by exposure to PHA. Lactate production by NTL was four times greater than that of enriched $T$ cells.

The extremely high glycolytic activity of NTM cells is due to the presence of a relatively high percentage of monocytes (Table 1). Indeed, glucose utilization and lactate production by a relatively pure population of monocytes far exceeded the metabolic activity of both $T$ cells and NTL. These high measured values of

Table 1. Composition of mononuclear cell populations studied

\begin{tabular}{lccc}
\hline \multicolumn{1}{c}{ T-cells $^{1}$} & $\begin{array}{c}\text { FC receptor } \\
\text { bearing cells }\end{array}$ & Monocytes $^{3}$ & \\
\hline & $(\%)$ & $(\%)$ & $(\%)$ \\
Whole mononuclear & $55-75$ & $15-30$ & $15-20$ \\
$\quad$ cells & & & \\
Enriched T-cells & $80-95$ & $5-10$ & $<3$ \\
NTM cells & $<5$ & $55-60$ & $25-35$ \\
NTL & $<5$ & $10-31$ & $<10$ \\
Monocytes & $<5$ & $<5$ & $>90$ \\
\hline
\end{tabular}

${ }^{1}$ Defined by E-rosette formation.

${ }^{2}$ Defined by EA-rosette formation.

${ }^{3}$ Defined by esterase stain. This stain shows an excellent correlation with assays for candida phagocytosis by monocytes. monocyte metabolism correlate well with estimated glycolytic activity of monocytes (estimated monocyte metabolism = NTM metabolism - 0.7 NTL metabolism/0.3).

The ATP content of subtypes of mononuclear cells was similar in all cell populations with the exception of the monocyte. The ATP content of the monocyte at time 0 was significantly higher than in the other cell groups (Table 3 ). In contrast to WMC, T cells, and NTL, monocyte ATP content diminished during the 3hr incubation.

Little glucose was metabolized via the TCA cycle by mononuclear cells under the conditions of incubation used in this study (Table 4). Significant HMPS activity was observed in all the mononuclear cell subpopulations tested.

\section{DISCUSSION}

The data presented demonstrate major differences in glycolytic energy metabolism among the partially purified subpopulations of mononuclear leucocytes studied. The separation technology employed allowed isolation of relatively pure populations of $T$ cells and monocytes. While it was possible to eliminate the vast majority of monocytes from the NTL population (only one sample tested had more than 5\% monocytes), this population consisted of a mixed population of $B$ and null cells. Current technology does not permit the separation of these 2 populations of lymphocytes in sufficient quantity to allow metabolic study.

Monocytes use glucose and produce lactate far more rapidly than all other populations of mononuclear cells. This is consistent with previous measurements of monocyte metabolism $(3,18)$. This increase can be partially attributed to the size of the monocyte, which may have as much as twice the cell volume of the lymphocyte. Preliminary data suggest, however, that monocytes are not a uniform population of cells (1). There appear to be at least 2 populations of human monocytes, one of a size approximately equal to that of lymphocytes, and one approximately twice the size of lymphocytes. These 2 populations are present in approximately equal numbers in the circulation of man. Thus, size alone cannot account for the metabolic differences observed.

It was further observed that the ATP content of monocytes was only slightly greater than that of lymphocytes. A calculated adjustment to account for cell size would equate the concentration of ATP in human monocytes and lymphocytes. In contrast to lymphocytes, however, the ATP content of monocytes diminished during incubation, in spite of the markedly increased glycolytic rate. The data suggest that monocytes use ATP more rapidly than lymphocytes and that the basal glycolytic rate of monocytes is closer to their maximal metabolic capacity.

The authors do not believe that the procedures used to isolate monocytes have significantly affected the metabolic data. Rabinovitch and DeStefano (11) have shown that the use of lidocaine does not interfere with monocyte function after the anesthetic is washed off. It seems unlikely that lidocaine significantly alters metabolism of monocytes since estimates of the monocyte contribution to NTM metabolism (made possible by their removal with iron) are similar to measurements of metabolism by lidocaineprepared monocytes. The NTL had the next most active glycolytic rate among mononuclear cells. This persistently heterogeneous population of mononuclear cells has not been subjected to metabolic study previously, and the data were surprising. The authors do not believe that this observation is the result of residual

Table 2. Glucose utilization and lactate production by enriched mononuclear cell subpopulations ${ }^{1}$

\begin{tabular}{|c|c|c|c|c|}
\hline & \multicolumn{2}{|c|}{ Resting metabolism } & \multicolumn{2}{|c|}{ PHA-stimulated metabolism } \\
\hline & Glucose utilization & Lactate production & Glucose utilization & Lactate production \\
\hline Whole mononuclear cells $(n=44)$ & $60 \pm 4$ & $104 \pm 6$ & $116 \pm 9$ & $187 \pm 12$ \\
\hline Enriched T-cells $(n=16)$ & $37 \pm 7$ & $55 \pm 12$ & $98 \pm 9$ & $124 \pm 13$ \\
\hline NTM cells $(n=16)$ & $231 \pm 20$ & $430 \pm 40$ & $242 \pm 15$ & $406 \pm 28$ \\
\hline NTL $(n=5)$ & $143 \pm 28$ & $236 \pm 53$ & & \\
\hline Monocytes $(n=15)$ & $348 \pm 23$ & $652 \pm 57$ & & \\
\hline
\end{tabular}

${ }^{1}$ Values expressed as mean \pm SEM. Units are nmole $/ \mathrm{hr} / 10^{7}$ cells. 
Table 3. ATP content in mononuclear cell subpopulations ${ }^{1}$

\begin{tabular}{cccc}
\hline & $\mathrm{N}$ & $\mathrm{ATP}_{0}{ }^{2}$ & $\mathrm{ATP}_{3}{ }^{3}$ \\
\hline WMC & 44 & $5.6 \pm 0.4$ & $5.6 \pm 0.4$ \\
T & 16 & $6.0 \pm 0.5$ & $5.6 \pm 0.4$ \\
NTM & 16 & $6.8 \pm 0.6$ & $4.8 \pm 0.4$ \\
NTL & 5 & $5.9 \pm 0.5$ & $5.5 \pm 0.7$ \\
M & 8 & $9.2 \pm 1.1$ & $5.6 \pm 0.5$ \\
\hline
\end{tabular}

${ }^{1}$ Values expressed as nmole $/ 10^{7}$ cells $\pm \mathrm{SEM}$.

${ }^{2} \mathrm{ATP}_{0}$ : ATP content at start of incubation.

${ }^{3} \mathrm{ATP}_{3}$ : ATP content after $3 \mathrm{hr}$ of incubation.

Table 4. TCA cycle and HMPS activities in mononuclear cell subpopulations ${ }^{1}$

\begin{tabular}{lcc}
\hline & TCA cycle & HMPS activity \\
\hline Whole mononuclear cells & $0.34 \pm 0.05$ & $5.72 \pm 0.91$ \\
& $(\mathrm{n}=6)$ & $(\mathrm{n}=9)$ \\
Enriched T-cells & $0.48 \pm 0.10$ & $3.82 \pm 0.29$ \\
& $(\mathrm{n}=5)$ & $(\mathrm{n}=5)$ \\
NTM cells & $0.29 \pm 0.07$ & $3.78 \pm 1.09$ \\
& $(\mathrm{n}=4)$ & $(\mathrm{n}=5)$ \\
\hline
\end{tabular}

${ }^{1}$ Expressed as mean \pm SEM. Units are $\%$ of glucose utilized.

monocyte contamination. Monocytes comprised less than $10 \%$ of this population in all samples studied, and, in only one instance, exceeded $5 \%$ of the cell population studied.

The authors cannot eliminate the possibility that the preparative procedures may have stimulated NTL metabolism, although there is no apparent reason to suspect this possibility. The technique of preparing E-rosettes might alter the membrane of $\mathrm{T}$-cells and cause an increase in the rate of energy metabolism. The authors compared the metabolic activity of T-cells prepared by nylon wool column adherence and by E-rosette formation. The authors were unable to document a significant difference in glucose utilization or lactate production (data not shown). It seems unlikely that a procedure (E-rosette formation) which directly affects T-cell membranes but not T-cell metabolism, would effect a change in NTL metabolism when the membranes of those cells are not apparently involved in the process.

The addition of particulate iron, which is then washed out of the system, would not be expected to alter NTL metabolism. Any effect on residual monocyte metabolism would be minimized by the low level of monocyte contamination. Furthermore, Cline and Lehrer (3) have shown that phagocytic activity by monocytes is not accompanied by increased glycolysis although a burst of HMPS activity does accompany phagocytosis (3). The authors observed no increase of HMPS activity in the NTL population after exposure to iron filings.

The largest portion of the NTL subpopulation of mononuclear cells is made up of lymphocytes which bear neither $\mathrm{T}$ nor B-cell markers. One might postulate that these "Null Cells" represent a more undifferentiated ("younger") population of lymphocytes. By analogy to erythrocytes, a young lymphocyte might possess a greater metabolic capability than an older, more differentiated, cell. Until more effective methods become available to harvest relatively "pure" Null cells, the youth and metabolic capacity of this class of cells must remain conjectural.

The data further show that the TCA cycle is not a major source of energy metabolism in mononuclear cells, under the conditions studied. Hedeskov and Esman (7) demonstrated, however, that lymphocyte oxygen consumption was inversely related to cell concentration. It is clear that because the TCA cycle is so much more efficient than glycolysis with respect to ATP synthesis, even small increases in TCA cycle activity could markedly alter cellular energy balance. The cell concentrations used in the experiments reported here were chosen to limit oxygen consumption and standardize the conditions of incubation within the limits of the accuracy of cell counting methods. The relevance of this or any other in vitro model system to actual in vivo metabolism is not clear. Significant HMPS activity was observed in all nononuclear cells.

It is important to recognize that both TCA cycle and HMPS activities are based upon measurements of glucose utilization. These data are derived from the observation of a small decrement in a large number. Thus, inherent inaccuracies are introduced into the calculations. The correlation between glucose utilization and lactate production lends some credence to the glucose utilization data but small changes in HMPS or TCA cycle activity under these conditions must be viewed with scepticism. The very minimal role of TCA cycle in the energy economy of all mononuclear cells (as measured under the described conditions) appears to be very real, however.

In summary, these studies emphasize the metabolic heterogeneity of mononuclear cells. Further studies are needed to define the metabolism of mononuclear cell subtypes. Some of these studies must await improved technology for the isolation of functional cell subtypes in adequate numbers to allow thorough metabolic study. It seems clear, however, that clinical correlations of metabolic observations require the metabolic study of relatively pure cell populations.

\section{REFERENCES AND NOTES}

1. Arenson, E. B., and Seeger, R. C.: Cell surface differentiation antigens of human mononuclear phagocytes. Clin. Res., 26: 183A (1978).

2. Boyum, A.: A one-stage procedure for isolation of granulocytes and lymphocytes from human blood. Scand. J. Clin. Lab. Invest., 21: 51 (1968).

3. Cline, M. and Lehrer, R.: Phagocytosis by human monocytes. Blood, 32: 423 (1968).

4. Das, M., Stiehm, E. R., Borut, T., and Feig, S. A.: Metabolic correlates of immune dysfunction in malnourished children. Am. J. Clin. Nutr., 30: 1949 (1977).

5. Das, M., Klein, W., and Feig, S. A.: Glycolytic metabolism of neonatal mononuclear cells. Pediat. Res., 11: 1026 (1977)

6. Graves, M. F., and Brown, G.: The purification of T and B lymphocytes. J. Immunol., 112: 420 (1974).

7. Hedeskov, C. J., and Esmann, V.: Respiration and glycolysis of normal human lymphocytes. Blood, 28: 163 (1966).

8. Hedeskov, C. J., and Esmann, V.: Respiration and glycolysis of normal human lymphocytes. Biochim. Biophys. Acta, 148: 372 (1967).

9. Hohorst, H. J.: L-(+)-lactate. Determination with lactic dehydrogenase and DPN in: H. F. Bergmeyer: Methods of Enzymatic Analysis. (Academic Press, Inc., New York, 1963) p. 266.

10. Jondal, M., Holm, G., and Wigzell, H.: Surface markers on human T and B lymphocytes: a large population of lymphocytes forming non-immune rosettes with sheep red blood cells. J. Exp. Med., 136: 207, 1972.

11. Rabinovitch, M., and DeStefano, M. J.: Use of the local anesthetic lidocaine for cell harvesting and subcultivation. In Vitro, 11: 379 (1975).

12. Saxon, A., Feldhaus, J. L., and Robbins, R. A.: Single step separation of human $\mathrm{T}$ and $\mathrm{B}$ cells using AET treated SRBC rosettes. J. Immunol. Methods, 12: 285 (1976).

13. Segel, G. B., Lichtman, M. A., Gordon, B. R., MacPherson, J. L., and Nusbacher, J.: Plateletpheresis residues: a source of large quantities of human blood lymphocytes. Transfusion, 16: 455 (1976).

14. Shapiro, R. S., Gerrard, J. M., Perry, G. S., White, J. G., Krivit, W., and Kersey, J. H.: Wiskott-Aldrich syndrome: detection of carrier state by metabolic stress of platelets. Lancet, 1 : 121 (1978).

15. Slein, M. W.: D-Glucose. Determination with hexokinase and glucose-6-phosphate dehydrogenase In: H. F. Bergmeyer: Methods of Enzymatic Analysis. (Academic Press, Inc., New York, 1963) p. 117.

16. St. John, J. B.: Determination of ATP in chlorella with the luciferin-luciferase enzyme system. Anal. Biochem., 37; 409 (1970).

17. Valentine W. N.: Hereditary hemolytic anemias associated with specific erythrocyte enzymopathies. Calif. Med., 108: 280 (1968).

18. Vanotti, A.: Metabolic pattern of leucocytes within the circulation and outside it. Ciba Found. Study Group 10: 79 (1961).

19. Zighelboim, J., Gale, R. P., Chiu, A., Bonavida, B., Ossorio, R. C., and Fahey, J. L. Antibody dependent cellular cytotoxicity: cytotoxicity mediated by nonT lymphocytes. Clin. Immunol. Immunopath., 3: 193 (1974).

20. The authors appreciate the critical assistance of Andrew Saxon, M. D. and the secretarial assistance of Ms. Angeliki Demos and Ms. Lisa Edels in the preparation of this manuscript.

21. This research was supported, in part, by grants from the United States Public Health Service (RR5354, CA 12800) and by the Karen Brigham Memorial Fund.

22. Requests for reprints should be addressed to: Stephen A. Feig, M. D., Department of Pediatrics, UCLA School of Medicine, Los Angeles, California 90024.

23. Received for publication August 8, 1978.

24. Accepted for publication March 14, 1979. 